\title{
MANUTENÇÃO DO AMBIENTE SEGURO E ADOLESCÊNCIA: um estudo baseado no modelo de atividade de vida
}

\section{MAINTAINING THE SAFE ENVIRONMENT AND ADOLESCENCE: a study based on the activity model life}

\author{
Eveline Pinheiro Beserra', Maria Dalva Santos Alves', Fabiane do Amaral Gubert', \\ Leilane Barbosa de Sousa', Vanessa Peres Cardoso Pimentel ${ }^{2}$
}

\section{RESUMO}

O objetivo deste estudo foi refletir com os adolescentes acerca das situações de vulnerabilidade do seu ambiente, baseada na atividade de vida de manutenção do ambiente seguro. Tratase de uma pesquisa-ação realizada com vinte e cinco adolescentes por meio de entrevista e oficina de promoção da saúde em uma escola pública em Fortaleza-Ceará, Brasil. Diante dos dados encontrados, verifica-se que muitas vulnerabilidades envolvem esses adolescentes na atividade de vida ambiente seguro, a saber: acidentes de trânsitos, assaltos, criminalidade, risco do contágio de doenças, como a dengue, e falta de compromisso com a vacinação. Logo, o enfermeiro deve compreender as especificidades dos grupos de adolescentes para intervir com estratégias dialógicas.

Descritores: Saúde do Adolescente; Promoção da Saúde; Enfermagem.

\begin{abstract}
The objective of this study was to reflect with adolescents about situations of vulnerability in your environment, based on the life activity maintaining the safe environment. This is an action research with twenty-five adolescents through interviews and workshop to promote health in a public school in Fortaleza-Ceará, Brazil. From the data found, it appears that many of these vulnerabilities involve adolescents in the activity of life insurance environment, for example: traffic accidents, assaults, crime, risk of spread of diseases, such as dengue, and lack of commitment to vaccination. Therefore, the nurse must understand the specificities of the groups of adolescents to intervene with dialogic strategies.
\end{abstract}

Descriptors: Adolescents Health; Health Promotion; Nursing.
${ }^{1}$ Doutora em Enfermagem pela Universidade Federal do Ceará (UFC), Fortaleza, CE, Brasil.

${ }^{2}$ Graduada em Enfermagem pelo Centro Universitário Estácio do Ceará (FIC), Fortaleza, CE, Brasil. 


\section{Introdução}

A adolescência é uma etapa da vida marcada por um complexo processo de crescimento e desenvolvimento biopsicossocial, fazendo-se necessária a adoção de novas práticas educativas que favoreçam o ganho de autonomia ante a exposição às diversas situações e riscos presentes e futuros para a saúde ${ }^{1}$. Assim, ao trabalhar com jovens é preciso instigar o mundo particular de suas vivências, desenhando sua realidade e dando margem ao desafio de penetrar nesse complexo viver, movido por emoções, sentimentos e expectativas do ser adolescente.

Em nossa sociedade atual, o adolescente encontra-se em situação de vulnerabilidade devido a algumas situações específicas, tais como acidentes, violências, além de envolver-se em discussões interpessoais. Nesse sentido, sabe-se que 12,9\% dos adolescentes brasileiros declararam ter se envolvido em alguma briga. Em relação à taxa de mortalidade, $50,5 \%$ das mortes tiveram como causa agressões (homicídios) e $27 \%$ foram causadas por acidentes de transporte 2.

À vista de tais indicadores, observam-se diversas situações de risco e vulnerabilidade que exigem intervenções coerentes com essa realidade. Assim, a promoção à saúde deste grupo deve atender as políticas públicas, com destaque para as diretrizes nacionais para a atenção integral à saúde de adolescentes e jovens, as quais discorrem sobre as principais vulnerabilidades e enfatizam a necessidade de estabelecer processos de intervenção intersetoriais e interdisciplinares voltadas para a saúde do adolescente ${ }^{3}$.

No âmbito da saúde, o Programa Saúde na Escola (PSE), atualmente, é visto como um desafio para a Estratégia da Saúde da Família, que tem diversas atribuições. Desde 2008, soma-se mais uma, que envolve o trabalho com uma clientela muito específica, o adolescente, caracterizando uma integração Educação e Saúde com vistas a garantir a saúde dos escolares, sendo, também, um meio de incentivar o protagonismo juvenil.

Alguns objetivos principais deste Programa são: promover a saúde e a cultura de paz, reforçando a prevenção de agravos à saúde; contribuir para a constituição de condições para a formação integral de educandos; concorrer para a formulação de sistema de atenção social, com foco na promoção da cidadania e nos direitos humanos e fortalecer 0 enfrentamento das vulnerabilidades, no campo da saúde, que possam comprometer o pleno desenvolvimento escolar ${ }^{4}$.

Logo, o enfermeiro pode inserir-se nesse espaço, uma vez que possui conhecimento, teorias e modelos de Enfermagem que podem ser aplicados com adolescentes na escola. O objetivo do estudo foi refletir com os adolescentes acerca das situações de vulnerabilidade do seu ambiente, baseada na atividade de vida de manutenção do ambiente seguro.

\section{Metodologia}

Trata-se de um estudo de abordagem qualitativa que utilizou a pesquisa-ação. Essa abordagem surge na partir da identificação do problema dentro de um contexto social e/ou institucional, do levantamento de dados relativos à situação problemática, da identificação da necessidade de mudança, do levantamento de possíveis soluções e, por fim, da intervenção ou ação, simultaneamente 5 . 0 estudo foi realizado numa escola de bairro periférico em Fortaleza-Ceará. O bairro em que foi desenvolvida a pesquisa possuía problemas, como saneamento básico inadequado, alto índice de criminalidade e baixo poder aquisitivo. Os vinte cinco adolescentes que participaram desse estudo encontravam-se na modalidade de ensino Educação de Jovens e Adultos (EJA).

A escolha desses jovens se deu por estudarem à noite e não serem beneficiados com as ações de Promoção da Saúde pela Estratégia da Saúde da Família. Encontravam-se na faixa etária entre os 15 e 18 anos.

O estudo ocorreu em duas etapas: a primeira consistiu em uma entrevista semi-estruturada individual desenvolvida em abril de 2011 e a segunda envolveram oficinas educativas que ocorreram em maio e junho de 2011. Este estudo baseou-se no Modelo de Enfermagem, nomeado Modelo de atividade de vida (RLT $)^{6}$, o qual é composto por 12 atividades de vida, a saber: 1) Manter um ambiente seguro; 2) Comunicar; 3) Respirar; 4) Comer e beber; 5) Eliminar; 6) Cuidar da higiene pessoal e vestir-se; 7) Controlar a temperatura do corpo; 8) Mobilizar-se; 9) Trabalhar e distrair-se; 10) Exprimir sexualidade; 11) Dormir; e 12) Morre. Destaca-se que, neste artigo, serão expostos somente os resultados das entrevistas e da oficina que contemplou a atividade de vida de manutenção do ambiente seguro.

Ressalta-se que cada oficina foi elaborada após as entrevistas, visto que estas proporcionavam maior interação, assim como a caracterização do grupo. Utilizaram-se vídeos provocadores de discussão sobre acidentes de trânsito, dengue e vacinação. A justificativa da utilização desses três itens estarem presentes na discussão desta oficina envolve a pretensão que os adolescentes refletissem sobre o autocuidado e sua corresponsabilidade na sociedade. 
Para análise dos dados, foram utilizadas as práticas discursivas. Constitui uma técnica de análise, definida como linguagem em ação, isto é, a maneira como as pessoas ao produzirem seus sentidos e opiniões, como se posicionam em seu âmbito social. São, portanto, os próprios repertórios interpretativos, compreendendo estes como o conjunto de termos e descrições que demarcam o rol das possibilidades de formulações discursivas, tendo por parâmetro o contexto em que essas práticas são produzidas ${ }^{7}$.

Foram respeitados os aspectos legais e éticos que envolvem pesquisas com seres humanos, conforme a Resolução $n^{0}$ 196/96, do Conselho Nacional de Saúde. Os participantes foram esclarecidos sobre todos os objetivos deste estudo, e de que os pais ou responsáveis precisavam assinar a autorização para a participação do menor no estudo, por meio do Termo de Consentimento Livre e Esclarecido. Logo, o estudo só iniciou com as assinaturas tantos dos adolescentes como de seus responsáveis. 0 estudo foi submetido à apreciação do Comitê de Ética em Pesquisa da Universidade Federal do Ceará e foi aprovado em reunião no dia 14 de março de 2011, cujo protocolo recebeu o número 038/11. Para manter 0 anonimato dos adolescentes. Utilizou-se o nome "Maria" para as meninas associado a uma letra, e para os meninos o nome "José" também acompanhado de uma letra.

\section{Resultados e Discussões}

Os participantes do estudo foram 12 meninas e 13 meninos. A maior parte das famílias dos adolescentes (20) possuía renda inferior ou igual a um salário mínimo. A maioria dos jovens do estudo morava com seus pais ou com um dos seus genitores (19); dentre os familiares, alguns residiam com avós e/ou tias. Havia também dois casos, entre os adolescentes do estudo, de união consensual. As residências foram construídas com materiais do tipo alvenaria. Os jovens, em sua maioria, moram em residências alugadas (20). Possuiam água encanada e rede de esgoto. $O$ lixo era coletado pela Prefeitura.

Essa descrição é importante para conhecer o ambiente no qual esse jovem vive e implementar a ação educativa de forma coerente com sua realidade. Em relação à segurança, alguns jovens afirmam que ocorriam poucos assaltos na rua onde moravam se comparadas com outras ruas da cidade. Outros se sentiam seguros por morarem perto de uma delegacia ou por caracterizarem sua rua como um ambiente familiar.

Já na visão sobre insegurança, eles listaram a marginalização, o uso e venda de drogas, os assaltos frequentes e a falta de sinalização, gerados de muitos acidentes, brigas entre vizinhos, "bebedeiras", morte por causa não esclarecida, como também estupros.

Os "becos" foram percebidos como os lugares mais perigosos, nos quais ocorriam assaltos com frequência.

Em um estudo com adolescentes num morro de Florianópolis, observou-se também a percepção de riscos no ambiente devido à presença do tráfico e outros crimes usualmente praticados. Os adolescentes/jovens atribuíram um risco por morarem em um local perigoso ${ }^{8}$.

A falta de sinalização nas ruas e avenidas, citada pelos jovens, é considerada como preocupante na sociedade, uma vez que os acidentes e as violências no Brasil configuram um problema de grande magnitude e transcendência de atenção para saúde pública. Os adolescentes e jovens são os mais afetados pela violência. Dados do ano de 2010 destacam que $43,3 \%$ das crianças e jovens são assassinados, $27,2 \%$ morrem devido a acidentes de transporte e $19,7 \%$ em outros acidentes. Essas três causas representam $90 \%$ do total de mortes de crianças e adolescentes por causas externas ${ }^{9}$.

Os jovens foram questionados se gostavam do local onde moravam. Eles afirmaram viver em um ambiente calmo, com vínculos bons de amizade e mencionaram o desejo de morar na mesma rua, caso necessitassem mudar. Os que não gostavam, afirmaram que a rua é muito perigosa devido aos assaltos e inimizades.

Os estudos existentes na literatura sobre a questão de gostar ou não do local que vivem foram desenvolvidos com adolescentes em situação de rua. Estes, muitas vezes, não gostam do ambiente que moram nem do ambiente familiar e optam por viver na rua ${ }^{10,11}$. Contudo, os adolescentes estudados não estão nesse perfil.

Outros jovens/adolescentes pela própria infraestrutura da casa e da rua, como a falta de asfalto e a presença de lixo nas calçadas. Um jovem descreveu que quando o caminhão de lixo coleta os resíduos, algumas vezes, o lixeiro deixa cair sacolas no meio da rua, acumulando mais lixo.

São diversas as consequências oriundas do lixo doméstico mal segregado, como poluição ambiental, presença de roedores, entre outros. Os adolescentes necessitam refletir sobre o meio ambiente, pois a saúde ambiental enseja oportunidades de debate sobre o desequilíbrio ecológico, bem como sobre ações nocivas diretamente ligadas à vida humana, mas também medidas de prevenção ${ }^{12}$. 
A manutenção do ambiente seguro é ação que promove e necessite da adoção de medidas e cuidados para evitar fatores de risco, como acidentes, higiene no lar, proteção no trânsito e cuidados de si. A prevenção é uma responsabilidade de todos $^{13}$. Esse conceito demostra a complexidade de manter $\mathrm{o}$ ambiente seguro, pois envolve uma reflexão grupal. $\mathrm{Na}$ oficina, focalizou-se a vulnerabilidade dos jovens nessa atividade de vida, abordando questões em torno da violência no trânsito e os cuidados com o ambiente na prevenção da dengue e vacinação.

Como descrito na metodologia, utilizaram-se vídeos provocadores de discussão. Optou-se pelos vídeos das campanhas publicitárias. Em relação à prevenção de acidentes de trânsito, utilizaram-se três vídeos para provocar a discussão na oficina educativa.

O primeiro retratava uma blitz, na qual identificavam pessoas alcoolizadas conduzindo seu veículo e afirmando ter consumido pouca bebidaalcóolica, contudo estavam visivelmente alcoolizadas. Este vídeo tinha como finalidade conscientizar as pessoas de que álcool e direção não combinam. O segundo vídeo demostrava as vulnerabilidades das crianças para acidentes de trânsito, e os motoristas, muitas vezes, displicentes com os cuidados no trânsito. E o terceiro vídeo era uma chamada à direção consciente pelo risco um condutor negligente, imperito e imprudente pode ocasionar no trânsito.

Os adolescentes perceberam pelos meios de comunicação o grande número de acidentes ocasionados por condutor alcoolizado. Portanto, infere-se que são necessárias ações de reflexão e conscientização sobre o uso de álcool e direção com a finalidade de tornarem-se futuros condutores conscientes que essa prática não combina.

A discussão sobre o uso de álcool entre adolescentes ocorrem devido ao abuso de álcool e outras drogas, os quais constituem as principais causas desencadeadoras de situações de vulnerabilidade na adolescência. Dados revelam a magnitude do problema para as diferentes esferas da sociedade, entre essas o setor de saúde, principalmente diante da constatação de que $25 \%$ de todas as mortes de jovens entre 15 e 19 anos são atribuídas ao álcool'14.

Em pesquisa realizada, identificou-se que menos de $85 \%$ dos jovens candidatos à primeira habilitação não conheciam alguém que tenha sido punido legalmente por beber e dirigir, $74 \%$ acreditavam que nenhum infrator receberia a pena legal e $64 \%$ consideravam mínima a chance de ser parado por policial ou sujeito a receber uma penalidade ${ }^{15}$.

Na discussão com os adolescentes do estudo, também foi dialogado sobre as penalidades de dirigir, após uso do álcool, que envolvem a perda da habilitação. O diálogo foi direcionado para o cuidado de si em não ingerir álcool e dirigir, quando estes optam por não ingerir álcool ao dirigir. Eles também foram alertados que no ato de dirigir envolve o cuidado com o outro, que pode ser o passageiro, o pedestre ou outro condutor.

\section{[...] pessoas bêbadas não devem dirigir porque podem causar um acidente (José D).}

A responsabilidade sobre as crianças são os adultos os pais, contudo também somos responsáveis pelo outro (Jose $H$ ).

Estes fragmentos retratam a realidade vivida por estes jovens, na qual as ruas são estreitas e as crianças brincam em um espaço, onde é reconhecido o risco de atropelamento. Além disso, observa-se na fala de José H a identificação de si, como corresponsável pelo bem-estar do outro.

Colocou-se esta situação para a reflexão dos jovens, para eles avaliarem suas posturas.

Não acontece só acidente com as pessoas que estão dentro do carro, mas também as que estão fora. Saiu na televisão que tinha cinco pessoas alcoolizadas voltando de uma festa e todos morreram. Por causa de um bêbado no volante todos os cinco morreram (Maria C).

[...] mas não é só o álcool tem pessoas que ultrapassam o limite de velocidade, não adianta a pessoa não está bêbada, mas está abusando da velocidade. Isso também causa acidentes (José $H$ ).

Maria C exemplificou uma realidade retratada com frequência na imprensa que são os acidentes de trânsitos ocasionados por condutores alcoolizados e, por fim, José H destacou a velocidade como uma imprudência dos condutores e a corresponsabilização.

A corresponsabilização no trânsito deve ser refletida de forma precoce para que o sujeito se aproprie do seu dever de cuidar de si e do outro, com vistas à promoção de um ambiente seguro. 
Os jovens do estudo identificaram que a forma segura de conduzir e se proteger estão todas legisladas, sendo necessário segui-las. A percepção de que eles perceberam o cuidado envolve o zelo consigo e como o outro, com vistas à qualidade de vida de ambos.

O elevado número de acidentes demostra que a violência no trânsito pode ser considerada um problema de saúde pública, que afeta todos os setores sociais, necessitando medidas de seguridade como alternativa e soluções ${ }^{16}$.

Outro ponto é a saúde ambiental, que contempla várias esferas. Contudo, nesse estudo optou-se por abordar somente a dengue, pois esta é hoje o mais importante arbovírus, por sua grande carga de doença e implicações sociais, tendo como vetor o mosquito Aedes aegypti, que se encontra com o homem no seu habitat doméstico e peridomiciliar ${ }^{17}$.

Utilizou-seumvídeoqueretratavaaarbovirose dengue eque descreviaações paraevitaresta doença. Epidemiologicamente a dengue no Brasil é crescente nas populações urbanas, caracterizando-se como um grande problema de saúde pública ${ }^{16}$.

Sabe-se que, para diminuir os casos de dengue, existe uma parceria entre os brasileiros e o Governo com ações de prevenção, pois envolve a conscientização de todos no combate às larvas do mosquito. A mobilização das comunidades na prevenção da dengue exige a continuidade de ações para o controle desse vetor.

Sobre 0 ambiente saudável na prevenção da dengue, emergiram alguns comentários, como não deixar água parada, colocar as garrafas voltadas para baixo, colocar terra nos jarros. Contudo, a discussão se direcionou para uma reflexão sobre a necessidade de cuidar do ambiente, focalizando a dengue como doença.

Eu tive dengue. É uma doença muito ruim sentia dor de cabeça, dor no corpo, dor nos olhos (José B).

José B relatou os sinais e sintomas que a dengue pode causar. Em um estudo sobre caso de dengue em TeresinaPiauí, Brasil observou-se que a forma hemorrágica da doença atingiu preferencialmente crianças de cinco a nove anos ${ }^{18}$. Outro estudo destacou que, nos últimos anos, os casos graves da doença na faixa etária mais jovem ${ }^{19}$.

Os meios de evitar a dengue surgiram algumas falas:

Uma pessoa só não vai conseguir acabar com a dengue, é preciso todo mundo junto para combater (Maria D).

Verifica-se que refletir sobre o ambiente é também refletir sobre a ação comunitária, pois todos necessitam realizar ações individuais para o bem comum Essa visão de coletividade foi ampliada para manutenção da saúde ambiental como um todo, fazendo com que os adolescentes refletissem sobre ações comprometidas com o bem-estar humano e ecológico.

Se não cuidarmos do ambiente podem trazer riscos não só para nós, mas para a comunidade (José D).

José D indagou: "Se há um foco de dengue na casa do vizinho, somente ele tem responsabilidade, ou todo 0 quarteirão?". O diálogo provocou outros questionamentos. O problema da dengue, muitas vezes, é visto como exclusivo do setor saúde, no entanto o que demostra a dificuldade de outros setores reconhecê-la como um objeto pertencente à sua área de atuação. Do mesmo modo, o vizinho com o foco na sua casa pode não se sentir responsabilizado pelo contágio da doença por outras pessoas não residentes em sua residência ${ }^{20}$. Da mesma forma, em outras pessoas que não residem com este, podem desconhecer o poder da ação comunitária no controle dessa doença.

Embora tenha ocorrido diálogo sobre a forma de transmissão e o combate ao vetor, a discussão voltou-se as ações comunitárias e a responsabilidade grupal do meio ambiente. A saúde ambiental é responsabilidade de todos, correlaciona-se com base na vida cotidiana, as suas necessidades e os interesses pessoais e coletivos. Um desajuste no controle do vetor da dengue acarreta a área desse desajuste, bem como da área adjacente ${ }^{21}$. Um desajuste no controle do vetor da dengue acarreta a área desse desajuste, bem como da área adjacente.

Em estudo realizado com 97 pessoas sobre dengue, observou-se que apenas 39,33\% acreditava ser fundamental informar a população para maior conscientização e mobilização da mesma no combate da doença. Logo, verifica-se a necessidade de resgate do papel população na prevenção desta doença22. 
Os jovens demostraram reconheceram que muitos adolescentes não têm consciência sobre isso ante essas afirmativas:

Nem todos, como jovens, se sentem responsáveis no combate à dengue (Maria G).

[...] na verdade, ninguém parou para prestar atenção nisso. As pessoas podem evitar esses focos de dengue. Aqui, no Brasil é assim, o Brasil está na lista dos países que tem muito lixo acumulado. Quando vem o período das chuvas, está acumulado lata, pneu, garrafas, vidros quebrados. Ai certas pessoas, são catadoras de lixo, tem ali o trabalho deles, ai pegam metal, alumínio, mas mais da metade da população não divide seu lixo, ocorre que coloca num lixo só, não separa, ai vem um gato, cachorro, abrem o lixo. E ele fica aberto, porque ninguém vai ajeitar, a chuva chega e cria o foco. A população não ajudou (José E).

A fala do José E exemplifica claramente o descaso de muitos em relação ao lixo. Nos períodos chuvosos, há 0 aumento da incidência dos casos de dengue em razão do acúmulo de lixo nas ruas. A água parada em diferentes recipientes, logo, favorece a proliferação do mosquito. Outro fato que foi retratado pelo adolescente foi o trabalhador informal que vive da reciclagem e que, muitas vezes, expõe o lixo, gerando odor e proliferação de roedores.

A saúde ambiental envolve uma reflexão contínua de ações para o bem-estar da população. Estas ações são importantes para a sensibilização e compromisso do cidadão diante do meio ambiente. Contudo, é necessário considerar as questões sociais, ambientais e econômicas como determinantes para promover um ambiente saudável e a saúde humana ${ }^{23}$.

Logo, para manter a saúde ambiental se torna necessário a corresponsabilidade de todos, bem como para impedir a proliferação do vetor da dengue. Na discussão grupal, a estratégia de prevenção da dengue foi entendida como possível, quando mediada pela participação de todos, afirmando que todos estão vulneráveis.

Outro aspecto que contemplou a atividade de vida de manutenção do ambiente seguro foi a vacinação. No Brasil, as estratégias de vacinação têm alcançado altos índices de eficiência, caracterizando-se como parâmetro para iniciativas semelhantes em outros países, firmando a "cultura da imunização" e se expressando na adesão da população aos programas de vacinação e demandas cada vez maiores ${ }^{16}$. É importante frisar que para saúde do adolescente existem vacinas a serem implementadas e, muitas vezes, os jovens percebem-se como não mais participantes de esquemas vacinais.

Na última temática dessa oficina, vacinação, utilizou-se um vídeo que tratava sobre a necessidade de vacinação para prevenção da rubéola e o compromisso com a prevenção de rubéola congênita. Foi escolhido esse vídeo sobre a vacinação contra rubéola, pois se trata de uma vacina importante para mulheres em período fértil e sendo transmitida por partícula, bem como no período do estudo não estava tendo nenhuma campanha específica pelo Ministério da Saúde.

\section{É importante se vacinar contra rubéola para não passar para o bebê (Maria G).}

O vídeo mostrou que o rapaz estava contaminado e deu lugar para uma grávida sentar dentro do ônibus, mas ele nem sabia que estava contaminado e podia passar para ela e ela passar para o bebê também (José E).

Aescolha desse vídeo foi exatamente para retratar a responsabilidade de cada um sobre si e, nesse contexto, indiretamente sobre o outro. Logo, a vacinação, embora se caracterize como ação individual, também proporciona uma proteção coletiva.

Discutiu-se sobre a importância da vacina na prevenção de diferentes doenças, emergindo dúvidas sobre a vacina contra o tétano e hepatite. Muitos jovens afirmaram não se recordarem da última vez em que se vacinaram. Outros retrataram realidades particulares:

Eu morava no interior e lá não tinha algumas vacinas, quando eu vim para cá perdi algumas por causa da idade, isso quando eu fui tomar H1N1 (José E).

José E percebeu a importância da vacinação e afirmou não ter o esquema vacinal completo. Ao término do encontro, os adolescentes perceberam que os cinco vídeos relacionavam saúde e segurança, contextualizando os temas propostos da oficina.

Foi solicitado que eles avaliassem o que haviam aprendido durante a realização da atividade. Observou-se que, na avaliação, emergiram questões que envolviam o cuidado no trânsito, cuidado com o ambiente na prevenção da dengue e a necessidade da vacinação; contudo, os jovens listaram outras reflexões: 
Segurança, prevenção, saúde (José H).

Isso me fez pensar que a segurança no trânsito é muito importante como a prevenção das doenças transmitidas pela relação sexual (Maria A).

Não dirigir bebo porque causa acidente e pode matar muitas pessoas. A dengue mata e todos têm obrigação de combatê-la (José A)

Os jovens afirmaram ter aprendido com os colegas a refletir sobre a segurança de si e dos outros. Maria A fez uma analogia com as doenças sexualmente transmissíveis (DST) e o trânsito. Esse tema no período da adolescência é muito atrativo, uma DST seja semelhante à prevenção dos acidentes de trânsito, enfatizando que ambas envolvem o autocuidado.

O uso do Modelo de Enfermagem, Modelo de atividade de vida, sobre atividade de vida manutenção do ambiente seguro permitiu uma prática reflexiva ampliada. Verificou-se, em outro estudo também, que o uso desse modelo promove o cuidado e a comunicação objetiva entre as pesquisadoras e os participantes, favorecendo autorreflexão ${ }^{24}$.

Em outro estudo que utilizou esse Modelo de Enfermagem com profissionais do sexo, foi possível obter o conhecimento mais detalhado conhecer as suas principais necessidades e vulnerabilidades por elas vividas no desempenho de suas atividades ${ }^{25}$.

Os jovens foram passiveis à reflexão, embora muitos tenham retratado os temas de forma estereotipada. A oficina educativa visava a refletir com os adolescentes visou gerar reflexões nos adolescentes acerca das situações de vulnerabilidade do seu ambiente. A reflexão sobre o jovem como capaz de cuidar de si sem desvincular o compromisso com a sociedade foi uma tentativa de romper com o paradigma do individualismo na adolescência, e assim levá-lo a perceber-se como um agente coletivo com força articuladora para mudanças.

Importante destacar o papel do enfermeiro como educador na escola. $O$ adolescente - ator das relações sociais e materiais, compreendido como um sujeito externo à sua dimensão psicológica, reveladora de aspectos relativos à sua subjetividade, mas com dimensões que demonstram um mesmo movimento produtivo - vive um período marcado por edificações de comportamento ${ }^{26}$. Nesse sentido, a enfermagem ganha importância no acompanhamento individual e coletivo, propiciando a escuta e o aconselhamento, numa perspectiva educativa e auxiliar na construção da sua autonomia ${ }^{27}$. Logo, o enfermeiro deve estar próximo ao adolescente para possibilitar um adolescer saudável.

É importante considerar o fato de que, o enfermeiro como educador em saúde, a pesquisa comprova, que gerando, a partir da intervenção, uma educação reflexiva e recíproca ${ }^{28}$.

\section{Considerações Finais}

Diante dos dados expostos, verifica-se que muitas vulnerabilidades envolvem os adolescentes na atividade de vida manutenção do ambiente seguro, a saber: os acidentes de trânsitos; pois eles conhecem condutores que dirigem alcoolizados e existem áreas próximas as suas residências percebidas como locais onde frequentemente ocorrem acidentes; os assaltos e criminalidade, pois residem em um bairro com alta incidência desses eventos; o risco do contágio de doenças, como a dengue, e a falta de compromisso com a vacinação. Logo, o enfermeiro deve compreender as especificidades dos grupos de adolescentes para intervir com estratégias dialógicas.

A enfermagem, como profissão autônoma, pode desempenhar diferentes atuações na gerência, pesquisa e educação, assim como na assistência, promoção e recuperação da saúde, sendo sempre subsidiada por teorias e modelos de Enfermagem que focalizam uma atenção personalizada e individualizada.

Nesse encontro, observou-se como o modelo de enfermagem RLT forneceu um conceito em sua atividade de vida "Manutenção do ambiente seguro" que permeou um direcionou para a discussão, sendo uma estratégia propícia para reflexão grupal e individual. Os elementos descritos nessa atividade, permitiram o conhecimento da realidade dos participantes de grupo, favorecendo uma discussão inserida no seu contexto cultural.

Salienta-se a necessidade da comunidade científica investigar diferentes formas de conhecer os adolescentes em suas vulnerabilidades, para sensibilizando-os a serem mais reflexivos e comprometidos com sua saúde. 


\section{Referências}

1. Penna G. Pesquisa Nacional de Saúde do Escolar (PeNSE). Cien Saude Colet. 2010;15(2): 3006-3006.

2. Ministério da Saúde (BR). Linha de Cuidado para a Atenção Integral à Saúde de Crianças, Adolescentes e suas Famílias em Situação de Violência. Brasília: Ministério da Saúde; 2010.

3. Ministério da Saúde (BR). Diretrizes nacionais para a atenção integral à saúde de adolescentes e jovens na promoção, proteção e recuperação da saúde. Brasília: Ministério da Saúde; 2010.

4. Ministério da Saúde (BR). Saúde na escola. Brasília: Ministério da Saúde; 2009.

5. Mitchell SN, Reilly RC, Logue M. E. Benefits of collaborative action research for the beginning teacher. Clin Teach. 2009; 25 (2): 344-349.

6. Roper N, Logan WW, Tierney AJ. O modelo de enfermagem: baseado nas atividades de vida diária. Lisboa: Climepsi; 2001. 7. Spink MJ. Práticas discursivas e produção de sentido no cotidiano: aproximações teóricas e metodológicas. São Paulo: Cortez; 1999.

8. Baggio MA, Carvalho JN, Backes MTS, Backes DS, Meirelles BHS, Erdmann AL et al. O significado atribuído ao papel masculino e feminino por adolescentes de periferia. Esc Anna Nery. 2009; 13(4): 872-878.

9. Waiselfisz JJ. Mapa da violência 2012. Os novos padrões da violência homicida no Brasil São Paulo: Instituto Sangari; 2011 10. Morais NE, Morais $A Q$, Reis $S$, Koller SH. Promoção de saúde e adolescência: um exemplo de intervenção com adolescentes em situação de rua. Psicologia \& Sociedade. 2010; 22 (3): 507-518.

11. Figueiredo JG, Aragão EMA. Crianças e adolescentes acolhidos: história tão verdadeiras que às vezes parece que são inventadas. Rev Epos. 2013; 4(2):00-00.

12. Beserra EP, Alves MDS, Rigotto MR. Adolescents' perception on environmental health: research-action in school space. Online braz j nurs [Internet]. 2010 March [Cited 2014 Aug 6]; 9 (1): Available from: http://www.objnursing.uff.br/ index.php/nursing/article/view/2740.

13. Freitas R, Santos SSC, Hammerschmidt KSA, Silva ME, Pelzer MT. Cuidado de enfermagem para prevenção de quedas em idosos: proposta para ação. Rev bras enferm.2011; 64(3): 478-485.

14. Hochman G. Vacinação, varíola e uma cultura da imunização no Brasil. Cien Saude Colet. 2011; 16(2): 375-386.

15. Bacchieri G, Barros AJD. Acidentes de trânsito no Brasil de 1998 a 2010:muitas mudanças e poucos resultados. Rev Saúde Pública. 2011; 45(5): 949-963

16. Cardona-Arbelaez, AS, Molina-Castano CF, Arango-Alzate CM, Pichott-Padilla JT.Caracterización de accidentes de tránsito y valoración tarifaria de la atención médica en el servicio de urgencias, Caldas-Antioquia 2007-2008.Rev Gerenc Polit Salud. 2010; 9 (19): 216-228.

17. Resendes APC, Silveira NAPR, Sabroza PC, Souza SR.Determinação de áreas prioritárias para ações de controle da dengue.Rev Saúde Pública. 2010; 44(2): 274-282.

18. Evangelista LSM, Oliveira FLL, Gonçalves LMF. Aspectos Epidemiológicos do Dengue no Município de Teresina, Piauí. Bol. Epidemiol. Paul. 2012; 9(103): 32-39.

19. Rodriguez BI, Cordeiro MT, Braga C, Souza WV, Marques ET, Cummings DA et al. From re-emergence to hyperendemicity: the natural history of the dengue epidemic in Brazil. PLoS Negl Trop Dis. 2011; 5:935.

20. Lima EC, Vilasbôas ALQ. Implantação das ações intersetoriais de mobilização social para o controle da dengue na Bahia, Brasil. Cad Saúde Pública, 2011; 27(8): 1507-1519.

21. Beserra EP, Alves MDS, Costa PN, Pinheiro NFCV. Educação ambiental e enfermagem: uma integração necessária. Rev Bras Enferm. 2010; 63(5): 848-52.

22. Villela EFM, Almeida MA. Representações sociais sobre dengue: reflexões sobre a mediação da informação em saúde pública. Saude soc. 2013; 22(1): 124-137.

23. Carneiro FF, Franco Netto G, Corvalan C, Freitas CM, Sales LBF. Saúde ambiental e desigualdades: construindo indicadores para o desenvolvimento sustentável. Cien Saude Colet. 2012; 17(6): 1419-1425.

24. Bezerra CP, Pagliuca LMF, Galvão MTG. Modelo de enfermagem baseado nas atividades de vida diária: adolescente diabética e deficiente visual. Esc Anna Nery. 2009; 13(4): 842-848.

25. Aquino PS, Nicolau AIO, Pinheiro AKB. Desempenho das atividades de vida de prostitutas segundo o Modelo de Enfermagem de Roper, Logan e Tierney. Rev bras enferm. 2011; 64(1):136-144.

26. Vieira SR, Rosenburg CP. A integralidade numa rede de proteção social ao adolescente: uma reflexão a partir do pensamento de Giles Lipovetsky. Saude Soc. 2010; 19(1): 127-134. 
27. Backes DS, Backes MS, Erdmann AL, Büscher A. O papel profissional do enfermeiro no Sistema Único de Saúde: da saúde comunitária à estratégia de saúde da família. Cien Saude Colet. 2012; 17(1): 223-230.

28. Nascimento AD, Hetkowski TM. Educação e contemporaneidade: pesquisas científicas e tecnológicas. Salvador: EDUFBA; 2009.

\section{Eveline Pinheiro Beserra}

Endereço para correspondência - Rua: Álvaro Fernandes, $n^{\circ} 891$,

Bairro: Montese, CEP: 60420-570, Fortaleza, CE, Brasil.

E-mail: eve_pinheiro@yahoo.com.br

Lattes: http://lattes.cnpq.br/2062308518368662

Maria Dalva Santos Alves - profadalvaalves@uol.com.br

Fabiane do Amaral Gubert - fabianegubert@hotmail.com

Leilane Barbosa de Sousa - leilane@unilab.edu.br

Vanessa Peres Cardoso Pimentel - nessaserep@hotmail.com

Enviado em 13 de agosto de 2014. Aceito em 22 de outubro de 2015. 
